\title{
GRIFFITHS, Naomi E. S., The Contexts of Acadian History, 1686-1784. Publié par le Centre d'études canadiennes, Université Mount Allison. Montréal et Kingston, McGill-Queen's University Press, 1992. xxi-137 p. 17,95 \$ \\ N. E. S. GRIFFITHS et G. A. RAWLYCK, eds., Mason Wade, Acadia and Quebec. The Perception of an Outsider. Ottawa, Carleton University Press, 1991. 198 p. 22,95 \$
}

\section{Margaret Conrad}

Volume 47, numéro 2, automne 1993

URI : https://id.erudit.org/iderudit/305227ar

DOI : https://doi.org/10.7202/305227ar

Aller au sommaire du numéro

Éditeur(s)

Institut d'histoire de l'Amérique française

ISSN

0035-2357 (imprimé)

1492-1383 (numérique)

Découvrir la revue

Citer ce compte rendu

Conrad, M. (1993). Compte rendu de [GRIFFITHS, Naomi E. S., The Contexts of Acadian History, 1686-1784. Publié par le Centre d'études canadiennes, Université Mount Allison. Montréal et Kingston, McGill-Queen's University Press, 1992. xxi-137 p. 17,95 \$ / N. E. S. GRIFFITHS et G. A. RAWLYCK, eds., Mason Wade, Acadia and Quebec. The Perception of an Outsider. Ottawa, Carleton University Press, 1991. 198 p. 22,95 \$]. Revue d'histoire de l'Amérique française, 47(2), 278-279. https://doi.org/10.7202/305227ar d'utilisation que vous pouvez consulter en ligne. 
GRIFFITHS, Naomi E. S., The Contexts of Acadian History, 1686-1784. Publié par le Centre d'études canadiennes, Université Mount Allison. Montréal et Kingston, McGill-Queen's University Press, 1992. xxi137 p. $17,95 \$$

N. E. S. GRIFFITHS et G. A. RAWLYCK, eds., Mason Wade, Acadia and Quebec. The Perception of an Outsider. Ottawa, Carleton University Press, 1991. 198 p. 22,95\$

Depuis l'époque de Longfellow, le nombre des historiens qui s'intéressent au passé acadien ne cesse de croître. Ces deux livres sont les fruits les plus récents de cette passion perpétuelle.

The Contexts of Acadian History s'appuie sur une série de conférences prononcées par Naomi Griffiths lorsqu'elle était titulaire de la chaire Bell d'études canadiennes à l'Université Mount Allison en 1988 et 1989. Pour mieux illustrer ses thèmes, madame Griffiths se concentre sur quatre périodes de l'histoire acadienne: la décennie de 1680, qu'elle qualifie de «début raisonnable de l'histoire acadienne»; les années 1730, «l'âge d'or de l'Acadie»; 1748-1755, les années qui précèdent la Déportation; et 1755-1785, les années d'exil.

L'objectif principal de ces textes est de placer les Acadiens dans un contexte plus vaste, tant celui de leurs antécédents européens que celui de l'Amérique du Nord. Pour ce faire, elle puise dans un vaste éventail de publications récentes sur les migrations transatlantiques et dans sa propre recherche menée des deux côtés de l'Atlantique. Ceci nous donne un court livre très original, écrit dans un style vivant, qui fouille dans des épisodes troubles, remet en question certaines idées reçues et offre un regard neuf sur des sujets connus. Iconoclaste, madame Griffiths suggère que la collectivité acadienne était composée de petits propriétaires agricoles et de métayers et non d'habitants et de paysans; qu'elle avait davantage de contacts avec l'extérieur, y compris avec la société micmaque et malécite; que la plupart des historiens sont prêts à l'avouer, le chiffre généralement accepté de 13000 Acadiens en 1755 oublie environ 5000 personnes; que les Acadiens étaient moins «neutres» qu'ils ne l'avaient prétendu aux autorités avant et après la Déportation, et que celle-ci serait un acte de guerre et non une «solution finale» ou un «massacre» selon la définition moderne «d'épuration ethnique». Par ces affirmations, l'auteure interpelle plusieurs grands spécialistes de l'histoire acadienne et québécoise et son audace sera sans doute critiquée.

On ne peut nier que madame Griffiths avance des idées innovatrices et évocatrices sur le comportement individuel et collectif des Acadiens avant 
1755. Le dernier chapitre du livre documente de façon déchirante les horreurs de la Déportation: naufrages, épidémies, exploitation et un taux de mortalité tellement élevé que l'existence d'une communauté acadienne de nos jours en est d'autant plus remarquable. On peut espérer que «l'œuvre maîtresse» de madame Griffiths, actuellement en cours, étoffera les thèses fascinantes ébauchées ici.

Un autre auteur d'une œuvre maîtresse, Mason Wade, a même été plus audacieux à son époque que Naomi Griffiths. La renommée de ce journaliste américain, qui ne maîtrisait pas le français, repose sur la publication du premier ouvrage de synthèse en anglais sur l'histoire du Québec depuis la Conquête. Après avoir terminé, Les Canadiens français de 1760 à nos jours en 1956, il s'est attelé à un vaste projet sur les francophones d'Amérique du Nord. À sa mort en 1986, il n'avait terminé qu'une partie de son œuvre, à l'état de brouillon, sur le «creuset maritime». Pour souligner la mémoire de leur ami, les compilateurs ont publié des extraits de son manuscrit (qui comprend des chapitres sur le Québec et l'Acadie, la Déportation des Acadiens, la Nouvelle-France et la Nouvelle-Angleterre, les Planteurs et la Révolution américaine, les Loyalistes), accompagnés d'un portrait biographique écrit par Naomi Griffiths et d'évaluations de sa carrière d'historien préparées par David M. L. Farr et Stephen Kenny (ce dernier l'a publié auparavant dans l'American Review of Canadian Studies). George Rawlyk, qui a été fortement influencé par Wade lorsqu'il étudiait à l'Université de Rochester, a signé une courte préface à saveur personnelle.

Le rassemblement de témoignages et de références bibliographiques en un seul volume est pratique, mais les compilateurs auraient davantage rendu justice à Wade en produisant un recueil de mélanges en son honneur plutôt qu'en publiant des extraits de son manuscrit. Comme les évaluations de sa carrière en font foi, Wade s'est appuyé en grande partie sur les travaux d'autres chercheurs. Ceci est flagrant dans certains chapitres qui sont essentiellement des condensés de J. B. Brebner et d'Esther Clark Wright. Fait encore plus malheureux, les nombreuses erreurs historiques et coquilles contenues dans le manuscrit se retrouvent dans la version publiée. À propos, tous les textes du livre auraient bénéficié d'une correction d'épreuves plus rigoureuse.

Bien qu'aucun des deux livres recensés ne soit l'ouvrage de synthèse tant attendu sur l'histoire acadienne, Contexts of Acadian History nous donne au moins l'espoir qu'une telle synthèse est non seulement possible, mais imminente. 